\title{
The ID21 beamline at ESRF: Sub- micron spectroscopy under cryo conditions for life and environmental sciences
}

\author{
HIRAM CASTILLO-MICHEL ${ }^{1}$, MARINE COTTE ${ }^{1}$, \\ MURIELLE SALOME ${ }^{1}$, DAVID BUGNAZET ${ }^{1}$, GIULIA \\ VERONESI $^{1,2}$, ANA E PRADAS DEL REAL ${ }^{1,3}$, LUIS

The ID21 beamline at the European Synchrotron Radiation facility (ESRF) is dedicated to micro X-ray fluorescence ( $\mu \mathrm{XRF}$ ) and micro X-ray absorption spectroscopy ( $\mu \mathrm{XAS})$ in the tender $\mathrm{X}$-ray range $(2-10 \mathrm{keV})$. It has an important scientific activity in the fields of life and environmental sciences, in particular for studying the fate of metals in the environment. This includes, e.g. the study of pollutants, nutrients and innovative drugs, with increasing applications in the field of nanotechnology. Elemental speciation determines the distribution at tissue and cellular level, and ultimately the various mechanisms of action. The chemical form and distribution of elements are also important to environmental risk assessment. These types of questions can be tackled thanks to the ID21 X-ray microscope.

Improvements have been done to offer a reliable and easy-tooperate passively cooled cryogenic stage, as well as the required auxiliary equipment for sample transport, storage and preparation. Thus, cryo-fixed samples are better preserved under intense X-ray beams and the elemental distributions, chemical states, and sample morphologies are close to the in-vivo state under frozen-hydrated conditions [1].

This presentation will highlight experiments performed at ID21 taking full advantage of these beamline capabilities to investigate the distribution and speciation of engineered nanomaterials in complex biological samples (plant [2] and animal tissue [3], and cells [4]). Finally, the future capabilities expected with the refurbishment of ID21 in the context of ESRFEBS upgrade will be presented.

[1] H. Castillo-Michel, C. Larue, A. Pradas del Real, M. Cotte, G. Sarret (2017), Plant physiology and biochemistry 110, 13.

[2] C. Larue, H. Castillo-Michel, R.J. Stein, B. Fayard, E. Pouyet, J. Villanova, V. Magnin, A.E. Pradas del Real, N. Trcera, S. Legros, S. Sorieul, G. Sarret (2016) Spectrochimica acta part B: atomic spectroscopy 119, 17.

[3] S. Smulder, C. Larue, G. Sarret, H. Castillo-Michel, J. Vanoirbeek, P. Hoet (2015) Toxicology letters 238, 1.

[4] D. Ferraro, I. Tredici, P. Ghigna, H. Castillo-Michel, A. Falqui, C. Di Benedetto, G. Alberti, V. Ricci, U. AnselmiTamburini, P. Sommi (2017) Nanoscale 9, 1527. 